\title{
Selling places: A community-based model for promoting local food. The case of Rhondda Cynon Taf
}

Dr. Robert Bowen, School of Management, Swansea University

Dr. Sophie Bennett , Aberystwyth Business School, Aberystwyth University

\begin{abstract}
Purpose: The aim of this paper is to evaluate how places approach the promotion of local food products and what it means to produce, consume and support local produce in a rural region.

Design/methodology/approach: The study uses a participatory action-reflective approach through a series of 3 focus groups held over consecutive weeks with 9 participants. This included local food producers, artists and community members, with data collected through focus group discussions, reflective video diaries and a questionnaire. Research was conducted in Rhondda Cynon Taf, Wales, a region with entrepreneurial potential but lacking a reputation for food.
\end{abstract}

Findings: Findings demonstrate confused perceptions of local identity, leading to a clichéd image of the region. As such, an origin brand may do little to enhance the value of local produce or increase economic prosperity in places that lack an established identity. Places with a more recognized reputation for food, such as Wales, could benefit from an origin brand, similar to Brittany.

Originality/value: The study extends the academic understanding of place branding by investigating the value in using origin branding in promoting food products. The context of a lesser-known region highlights the importance of awareness and reputation for the successful implementation of the brand. Additionally, the unique community-led action-reflective methodology provides a holistic model in exploring the effective development of the brand.

Key words: Place, Country-of-Origin, Food, SME, Labelling 


\section{Introduction}

The aim of this paper is to explore how regional food SMEs may develop a competitive advantage by building upon local cultural advantages, focussing on the Rhondda Cynon Taf area of Wales. Globalisation has brought homogenisation, as places start to resemble one another all over the world. This is manifested in fast food outlets, airports or shopping malls, spaces disconnected from the local environment, suggesting that place attachments are no longer as strong (Cresswell, 2004). Relph (1976) equated this to 'placelessness', an inability to have authentic relationships to place due to the sameness of modern places. This is attributed to mass culture - the mass movement of people, tourism and growing Disneyfication, museumisation and futurisation of places. Globalisation has caused a loss of a sense of place, as homogenised global spaces have eroded cultures (Cresswell, 2004). For Massey (1991), a global sense of place is expressed through the multiple identities and histories of place, with place uniqueness defined by its interactions.

The UK food industry has faced difficult periods over recent decades which, in some respects, has created advantages for small, local, food producers; for example, both the BSE scandal during the 1990s and Foot and Mouth Disease in the early 2000s led consumers to question the origins of food, placing more emphasis on traceability (McElwee et al., 2017). Consequently, consumers are increasingly showing more faith in local producers, some of whom have grown from a presence at local farmers' markets to international trade. However, while consumers may be turning to more local, traceable, sources, this has not yet produced a significant increase in growth for food SMEs operating in certain regions, indicating that the distinctive value of regional produce has not yet been recognized in all parts of Wales. This is especially true for regions which are not currently known for their produce, such as Rhondda Cynon Taf (RCT), where only 19 food and drink SMEs are located. Compared to culturally similar regions, such as Scotland or Brittany, Wales does not derive the same economic value from regional produce. For example, the value of exports across the Welsh food industry in 2017 amounted to $£ 527.4 \mathrm{~m}$ (Food and Drink Wales, 2018), whilst exports amount to £4.37bn in Scottish Whisky alone (Scotch Whisky Association, 2018). This leads to the question of whether, given its socioeconomic similarities, regional food SMEs in Wales may develop a competitive advantage by building upon local cultural advantages in the same way.

Food products are both made by and shape the territory from which they are derived (Pike, 2009), in many cases developing world acclaim for their geographic location, such as Scotch Whisky, Champagne or Parma Ham (Tregear \& Gorton, 2005). Welsh examples include Welsh Lamb and Caerphilly Cheese. Origin brands such as these are evident on national, regional and sub-regional levels, examples include Made in Cornwall, administered by Cornwall Council (Cornwall Council, 2017), New Zealand Made, managed by a business advocacy organisation (Buy NZ Made, 2018), and Produit en Bretagne, developed and managed by producers in Brittany (Produit en Bretagne, 2018). Produit en Bretagne is a prominent example of a region using local produce to enhance regional prosperity. The logo is part of a brand that adds value to food products, promoting sales in both domestic and international markets. Consequently, this paper seeks to evaluate the significance of regional branding to food products from Rhondda Cynon Taf.

Rhondda Cynon Taff (RCT) was selected as the location for this study, as a region not known for regional food products. RCT is the second largest Local Authority in Wales, formed in 1996 under the Local Government (Wales) Act from the former Boroughs of Rhondda, Cynon Valley and Taff Ely (part). Overall prosperity is low, as a region that has experienced deindustrialisation, but RCT appears to show high levels of entrepreneurial activity, with $89.1 \%$ of businesses operating as micro enterprises and 9.2\% operating as small businesses (ONS, 
2011). The Rural Action Cwm Taf Local Action Group, which partly covers the RCT area, includes Food Action Plans as part of its regional development plan supported by the EU LEADER programme (Welsh Assembly Government, 2014). Therefore, while this area is currently under-performing economically, there appears to be potential for local food businesses to contribute towards prosperity. Although food producers exist in RCT, including one of Wales' most recognizable businesses, Penderyn Whisky, it is not known for its regional produce and does not use regional branding. This implies that there is scope for the promotion of local produce to increase sales, which could contribute towards the future growth of this area. As such, this paper investigates how local culture can be leveraged to develop a competitive advantage in promoting foods from Rhondda Cynon Taf.

\section{Literature Review}

This section discusses the relationship between food and place, seen as either natural or socially constructed, and how place identities can be used to develop a competitive advantage. The close associations between food and territory are such that typical local foods are embedded in the cultural heritage of its location (Tregear, 2001). This relationship is akin to Relph's (1976) discussions of having a deep sense of place, evidenced in the French concept of terroir, the notion that wines reflect local physical conditions of production, particularly climate, topography and soil (Barham, 2003). This is true for Champagne, associated with its region of France (Tregear \& Gorton, 2005). Regional foods have historical associations with their local region, often evoking characteristics of the local socio-economic situation, and unique climatic and geographic characteristics (Tregear et al., 1998). An example is the cultural influence of Cornish pasties, a dish for miners with meat in one end and jam in the other, underlining connections that foods have with local customs, part of local heritage and identity (Figure 1).

Figure 1: Regional food characteristics

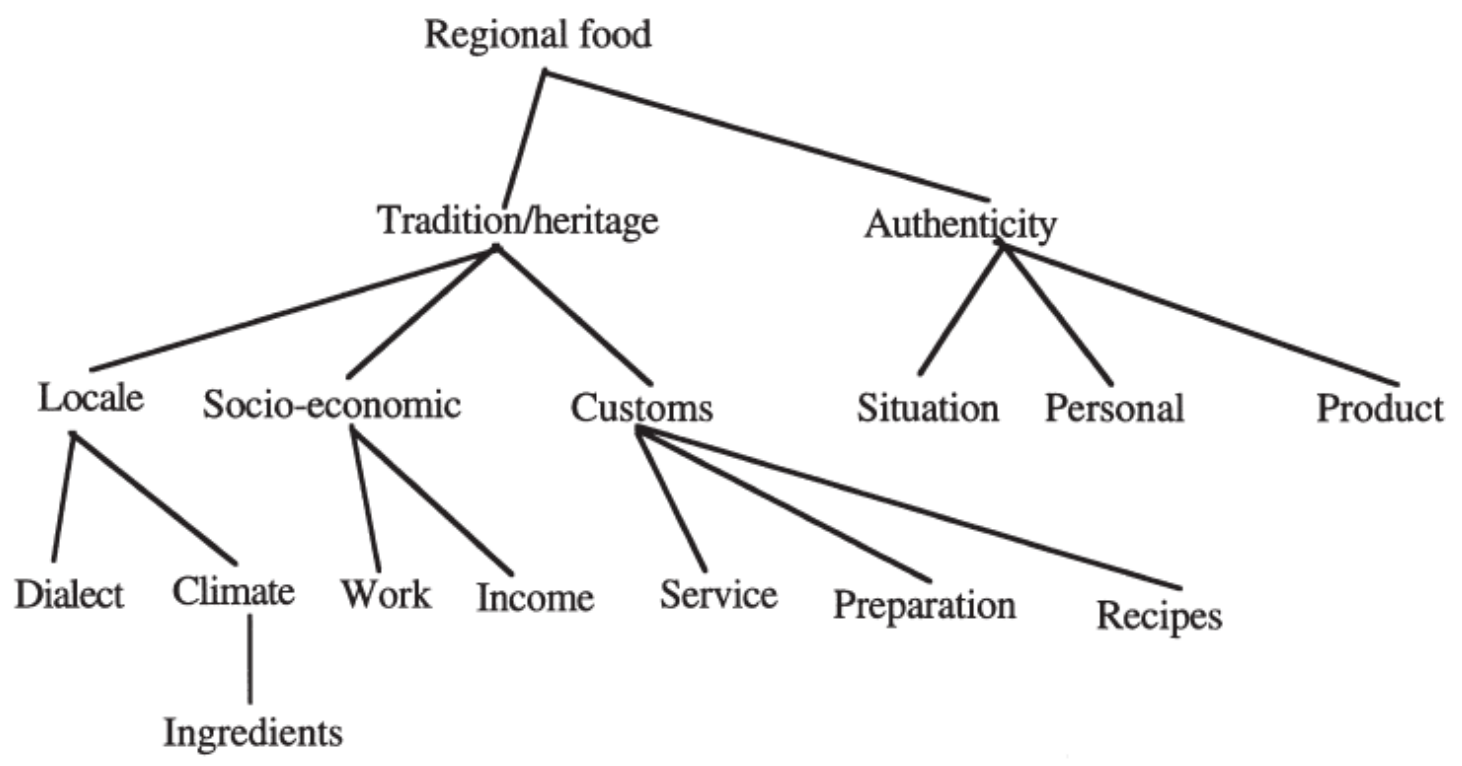

(Tregear et al., 1998, p. 388)

Considering Relph's (1976) discussions of authenticity to place, the inclusion of authenticity as a characteristic of regional foods strengthens the links between food and its place of origin. Authenticity is influenced by situational, personal and product factors. This includes the place and context of the purchase or consumption of foods, with specialist retail outlets seen to be associated with authentic local products, as well as people's knowledge and first-hand 
experience with certain products, which along with product-related factors, such as the name, label, appearance, packaging or description, enhance the perceived authenticity of regional foods (Tregear et al., 1998). Culture-territory associations are rarely seen to be embedded within products, with the exception of agri-food brands due to their particular non-replicable, substitutable, or even organic ties to certain places (Pike, 2009). Such uniqueness is echoed in Resource-based View (RBV) theory, notably the VRIN model, which identifies valuable, rare, inimitable and non-substitutable attributes within resources to enhance competitive advantage (Barney, 1991). Given the close associations between foods and their places of origin (Tregear, 2001), the unique resources of place, as expressed in terroir, provide foods with a competitive advantage (Testa, 2011), as these characteristics are inimitable. This is manifested in protected food names, products that have intellectual property protection to underline the unique linkages of the products to places, such as Champagne, Cheddar Cheese or Welsh Lamb.

\subsection{Social Construction}

With "multiple layers of meaning” (Harvey, 1996, p. 208), place is open to social construction which can be appropriated, associated and/or projected in and through brands or branding (Pike, 2009). Contrary to the inherent nature of food-territory relationships discussed above, brand qualities can be socially constructed to enable and support price premiums related to brands, thus demonstrating the monetary value of the brand (Pike, 2009). Places have histories of economics, politics, gender, class, ethnicity and a variety of stories, the construction of a place is therefore considered the result of these histories (Allen et al., 1998). However, through social construction, places can be seen as 'products' sold in a variety of ways (Warnaby \& Medway, 2013), with place branding providing a narrative to places, bringing attachment to the place by both internal and external audiences, and providing competitive advantage (Colomb \& Kalandides, 2010). Castree (2001) reiterates the social construction of place, seen through adverts, labels, trademarks, copyrights or billboards, which present questionable yet effective images of places and cultures.

Brands can be a powerful means of evoking preferred images of products, services or places (Morgan et al., 2007). Places can differentiate themselves through strong and positive brand images (Kotler et al., 1997), indeed, a strong and positive reputation represents an extremely valuable asset for any place, product or service (Anholt, 2016). Country-of-origin branding, including 'Made in...' labels, can influence consumer perceptions of products that are inherently similar to those originating in other locations (Baker \& Ballington, 2002). Tellström et al. (2006) point to strong images related to the product, evoking strong visual expressions of origin, such as landscapes, people and stereotypical rural imagery. Images relating a product to a country are often seen as stereotypical and based on general impressions or idiosyncratic beliefs of the country and its products, which consumers have shaped around previous experiences (Bilkey \& Nes, 1982). Essential to the product is the brand logo, a memorable visual cue that is “the most crucial semiotic mediator for meaning within a company's verbal and visual promotion strategies" (Imene \& Georges, 2012, p. 4). This can be expressed either through a region of origin label, or a brand with a regional reference.

\subsection{Place Identity}

The powerful sociocultural associations of food with place is a critical symbolic determinant of identity (Kingsolver 2003). Consumers use their awareness of the region of origin to shape their perceptions of the general quality of the regional product (Imene \& Georges, 2012). Origin-labelled food perceptions represent more than the transfer of a country stereotype to a product, it represents an affection, depicting pride, tradition, nostalgia or exoticism (Fournier, 
1998; Verlegh \& Steenkamp, 1999). Roth and Romeo (1992) argue that consumers' evaluations of a product are based on the match between the product and the country of origin in relation to the perceived strengths of the country and the skills needed in producing the product in question. For example, a preference for German cars could be born of the perception of workmanship of German engineers and the country's reputation for technological advancement. Labels of origin have the potential to associate production with socio-cultural and environment aspects of places, which act as a means of differentiating products from that place against more anonymous generic products (Barham, 2003).

Branding strategies aimed at creating differentiation through geographic entanglements recognize that "products are not made in 'countries', they are made in 'places'”. This could constitute any form of place from a city, province, country, region, continent or even the world" (Papadopoulos, 1993, p. 4). Spatial distinctions are often blurred and undefined and the words 'local' and 'regional' can evoke a multitude of meanings on varying degrees of scale. The 'national' geographic entanglement is certainly important, however this may not always represent the most meaningful depiction of place for certain goods or services (Pike, 2009). Support for a Welsh origin label was observed among Welsh beef and lamb producers by Kneafsey et al. (2001) due to the historical embeddedness of upland farming in West Wales and consumers' strong association of beef and lamb within the territory. Positive consumer perceptions of Wales were associated with natural, green, low-intensity farming and its mountainous terrain, however concerns were raised over the effectiveness of sub-regional promotion, since awareness of sub-regions, such as Welsh Black Beef or Saltmarsh Lamb, is likely to be limited. Other food sectors showed varying experiences in using cultural marketing. Organic food producers, particularly fruit and vegetables, placed more emphasis on product quality rather than cultural marketing, which was seen more favourably among speciality cheese producers, who appreciate that Welsh images and place names evoke 'Welsh' characteristics which are valuable to them.

\subsection{Place Revalorisation}

This section has discussed the close connections between food and place and the advantages that foods can derive through their unique characteristics of place. Food products can be seen as a reflection of the identity in some places, as Everett and Aitchison (2008) highlight the intrinsic nature of food to regional identity. Through fixing a product to its territory, the locality is able to gain greater economic benefit, which serves to strengthen local culture. Furthermore, Ray $(1998$, p. 3) discussed ways in which rural areas attempt to "(re)valorise place through its cultural identity”. He pointed to the 'cultural economy' as an approach to rural development in response to extra-local pressures that impact on the socio-economic vibrancy of local areas in a globalised world. Culture is a key resource, with many areas turning to cultural markers in order to pursue regional development. It concerns the creation and valorisation of place-identity resources that can be used in marketing the product or territory, such as in cultural tourism or agri-food products. The Kneafsey et al. (2001) study raised questions over the possible benefits of using territorial identity to market a product according to its place-of-origin. In the aforementioned study although many Welsh food companies were in favour of this, some producers were concerned over the protection of spatial identities. Certainly, it can be considered that this is an area that requires more research to measure how effective a regional brand could be. This paper aims to address this issue, investigating the value of building upon local cultural advantages by developing such a brand for Rhondda Cynon Taf. 


\section{Methodology}

This research followed the action-reflection plan designed by Lewin (cited in McNiff et al., 1996, p. 40) documented in figure 2.

Figure 2: Action-reflection cycle for research

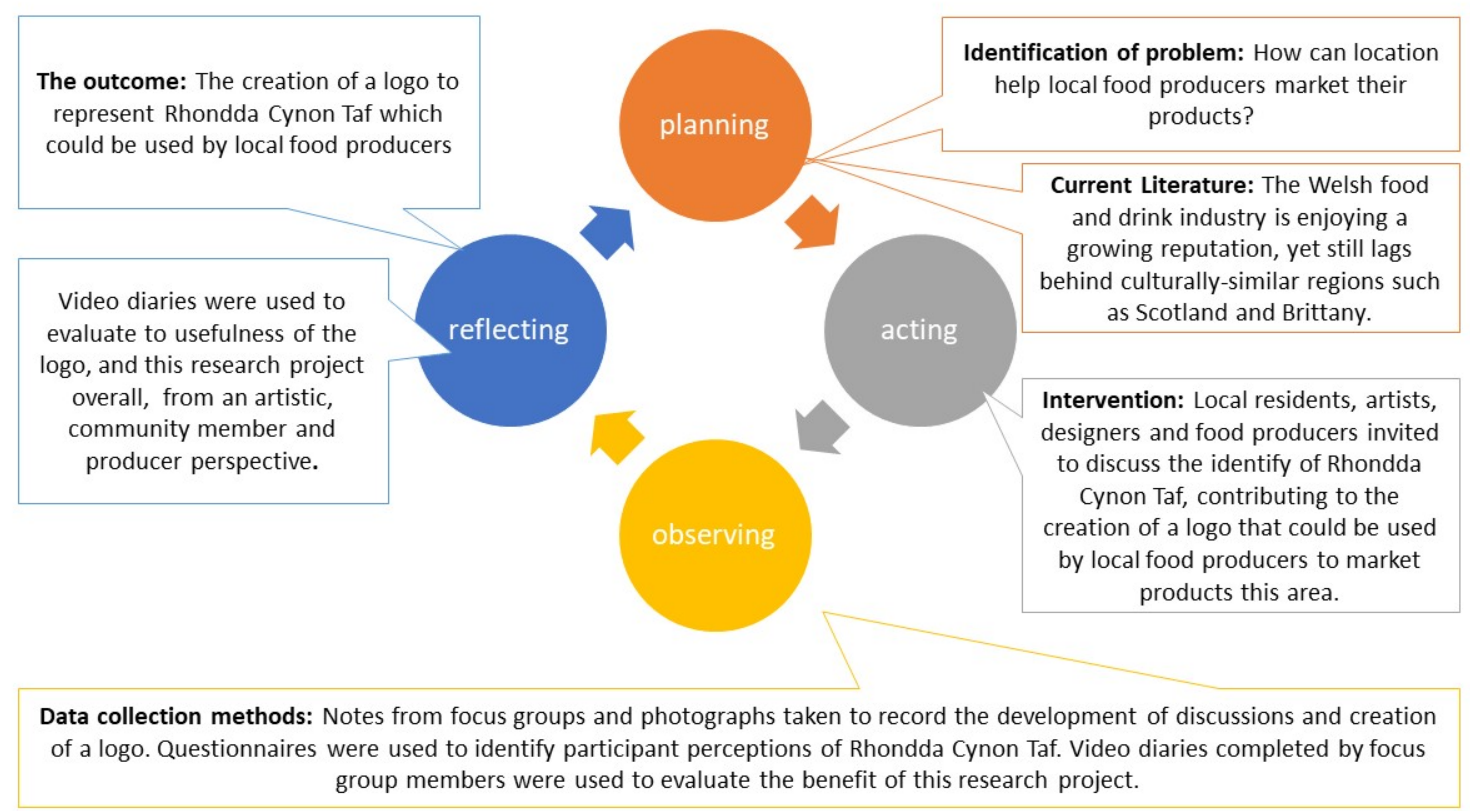

adapted from McNiff, et al. (1996)

Data was collected from a series of 3 focus groups held with 9 participants in Pontypridd over consecutive weeks. Members of the focus group were selected from local arts organisations and community groups, with invitations also sent to 19 food producers in RCT identified by the Food and Drink Wales Directory (Zero2Five, 2014). Data was obtained through focus group discussions, reflective video diaries and a questionnaire. This qualitative approach was followed to investigate participants' perceptions within a natural setting (Miles et al., 2014). The aim was to unite local residents, artists, designers and food producers in a community-led approach to discuss their interpretations of local identity. These discussions led to the creation of a logo for local food producers to market food products from Rhondda Cynon Taf.

Focus group discussions centred on a progressive theme building towards the design of a logo (Figure 3). Workshops began by asking participants to reflect on their experience of living in RCT (workshop 1), their knowledge and consumption of local produce (workshop 2) and finally, visual images that identify RCT for visitors or community members. Activities were led by the research team and assisted by an artist and a local designer, who was designated with the task of creating the logo, based upon participants' responses within the focus groups. 
Figure 3: Focus group contents
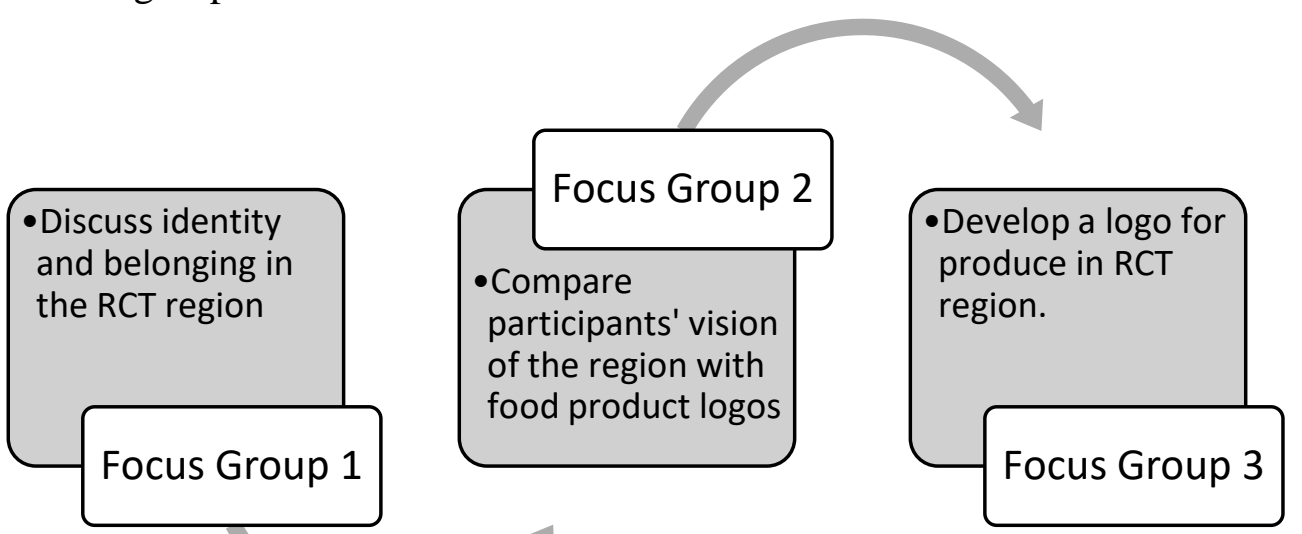

Each session was audio-recorded and participants were asked to complete individual video diary entries in an adjacent room, which were used to evaluate the benefit of each workshop activity and the project overall. During these, participants were asked to reflect on the perceived benefits of this type of project for food producers and the local community, the potential of this type of project to make a difference to the future of food production, and whether this project has changed participants' understanding of the way local businesses, artists and the community can work together. At the end of the project a questionnaire was administered. Participants were asked to comment on their perspective of RCT, identifying visual images or symbols specific to this location, as well as evaluating their perception of economic activity within the area. The latter asked participants to comment on their general standard of living, their consumption of local produce and any interaction between business and the local community. Data from all sources was collated and analysed following the Braun and Clarke (2006) method of thematic analysis to draw key issues from the qualitative data, using first and second coding cycles (Miles et al., 2014). Table 1 outlines the profile of the participants.

Table 1: Profile of participants

\begin{tabular}{|c|c|c|c|c|c|c|}
\hline Participant & Age & Occupation & Origin & Gender & $\begin{array}{c}\text { Time } \\
\text { living in } \\
\text { RCT }\end{array}$ & $\begin{array}{c}\text { Reason for } \\
\text { moving to } \\
\text { RCT }\end{array}$ \\
\hline A & $18-24$ & Art student & Bulgaria & Female & 1 year & University \\
\hline B & $18-24$ & Art student & Norway & Female & 1 year & University \\
\hline C & $18-24$ & Art student & England & Male & 6 months & University \\
\hline D & $18-24$ & Art student & England & Female & 1 year & University \\
\hline E & $25-34$ & Art student & England & Female & 3 years & University \\
\hline F & $35-44$ & $\begin{array}{c}\text { Food } \\
\text { producer }\end{array}$ & England & Female & 10 years & $\begin{array}{c}\text { House } \\
\text { prices }\end{array}$ \\
\hline G & $35-44$ & $\begin{array}{c}\text { Food } \\
\text { producer }\end{array}$ & RCT & Female & Lifetime & - \\
\hline H & $45-54$ & $\begin{array}{c}\text { Food } \\
\text { producer }\end{array}$ & RCT & Female & Lifetime & - \\
\hline I & $55-64$ & $\begin{array}{c}\text { Food } \\
\text { producer }\end{array}$ & RCT & Female & Lifetime & - \\
\hline Designer & $45-54$ & Designer & RCT & Male & Lifetime & - \\
\hline Artist & $35-44$ & Artist & England & Female & $\begin{array}{c}\text { Over } 5 \\
\text { years }\end{array}$ & Work \\
\hline
\end{tabular}


The inclusion of participants that are native to RCT and those who have moved to the area is significant for the study, as this brings a variety of interpretations of the region, from those that have experienced the changes to RCT over their lifetimes, to the early impressions of those who have limited experience of living in the area. Participants not originally from RCT also bring external interpretations of the region, which is especially important in understanding how the logo could be used to promote the region.

\section{Findings}

The thematic map in Figure 4 outlines the three themes that emerged from discussions. Firstly, identity relates to the feeling of community belonging, the second documents feelings towards the local socio-economic situation, and the third points to the potential value of a logo in marketing local produce.

Figure 4: Thematic map

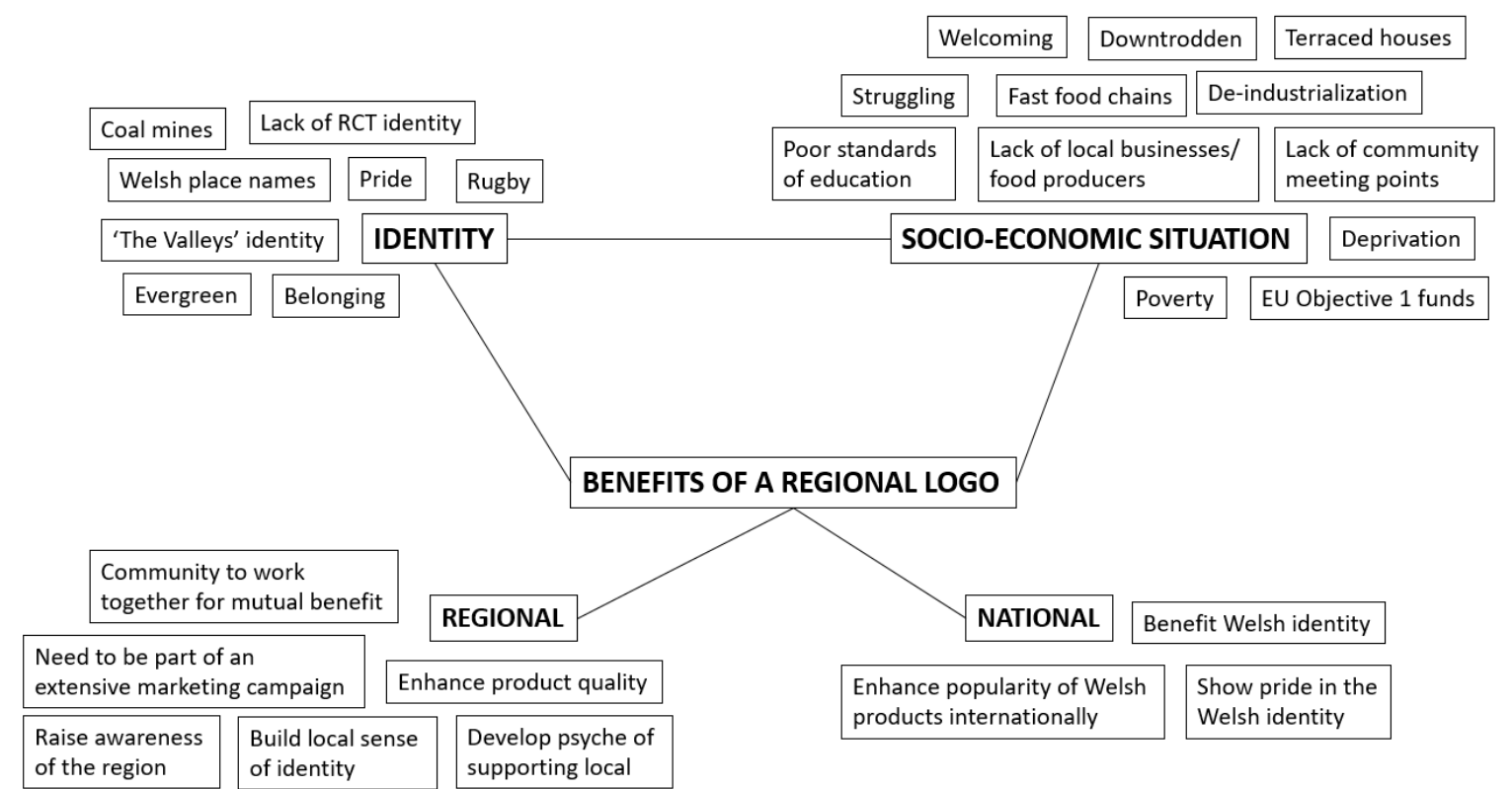

\subsection{Identity}

Discussions on identity centred on the participants' feeling of belonging to Rhondda Cynon Taf, as well as how RCT was perceived outside the region. A key point was the apparent lack of identity of the region, with several participants stating that they were unaware of which towns were actually part of RCT, and where the county boundaries lay. Participants born and raised in the area did not identify themselves as being from RCT. It became apparent that the area had no clear identity, since it was manufactured in 1996 following the Local Government (Wales) Act of 1994. As such, the area was seen to exist purely for administrative reasons. For those who had moved into the area, RCT as an entity meant very little, claiming to have never heard the name before moving to the area: 'I've heard of the Valleys before, but I'd never heard of Rhondda Cynon Taf before I moved here’ (Participant E).

'The Valleys' was more commonly recognized as an area that participants could relate to. Although not a defined area, participants originally from outside Wales were aware of 'The Valleys', and participants originally from RCT admitted to referring to themselves as being from 'The Valleys' when speaking to people from outside their local area, or they tended to refer to their town or valley of origin. Comprised of the Rhondda, Cynon and Taf valleys, the 
RCT region represents 3 of the 21 valleys considered to be part of the South Wales Valleys. As such, RCT alone cannot be considered representative of 'The Valleys', however, the name and its identity can be seen to have been derived from a shared socio-cultural heritage evident across South Wales since the age of industrialization. Discussions of identity highlight the complexities of regional identities that exist in Wales, this is evident in the Three Wales Model (Balsom, 1985), which distinguishes between their defined identities of British Wales, Welsh Wales and 'Y Fro Gymraeg' ('The Welsh Country', used to define the Welsh-speaking heartlands of Wales). Established on patterns of voting behaviour, class, language and national identity, the current relevance of this model is questionable, however, the Welsh Wales identity (Figure 5) represents the area referred to as 'The Valleys', underlining the significance of the wider Valleys region at the heart of Welsh identity.

Figure 5: The Three-Wales Model

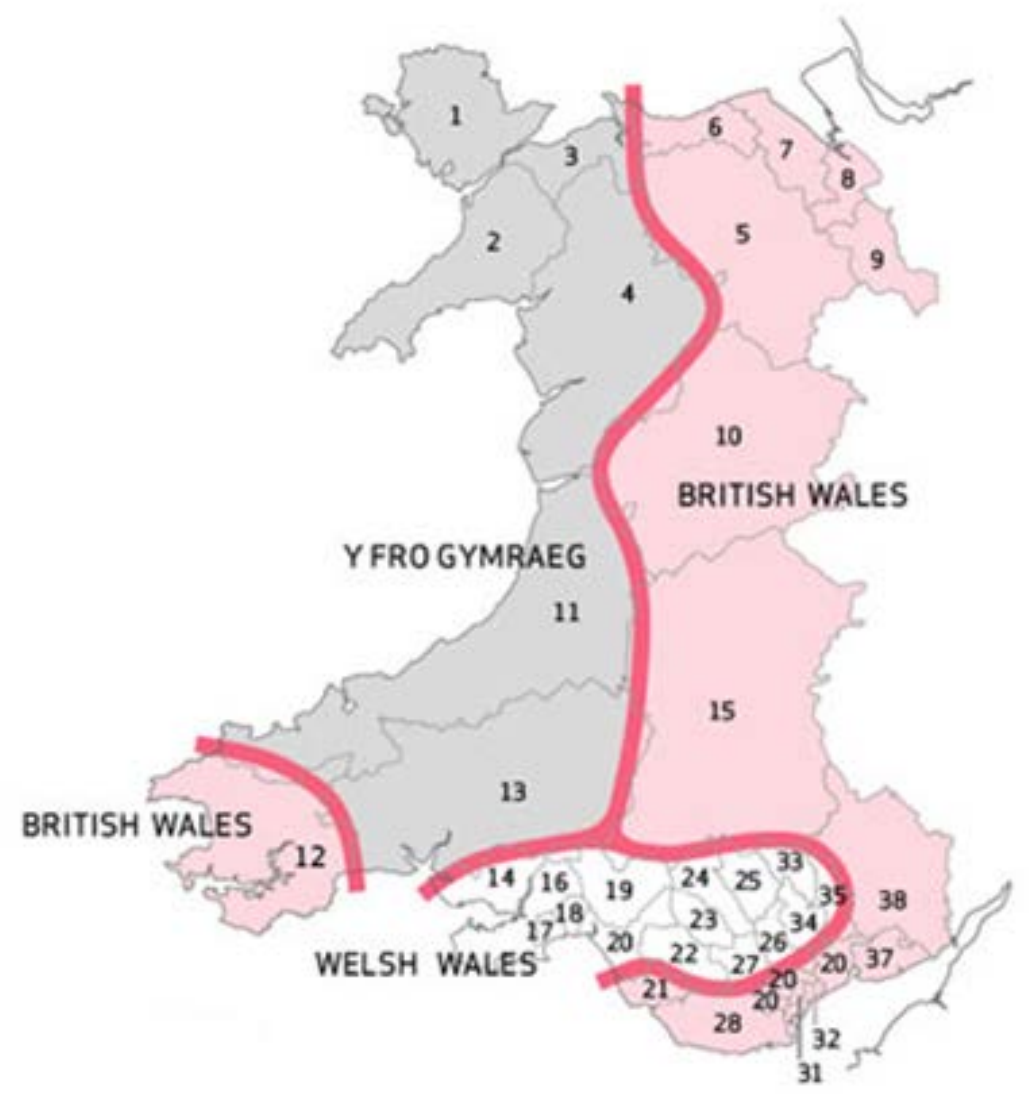

Balsom (1985)

Although not recognized as a Welsh-speaking heartland under the Three Wales Model, the Designer, a fluent Welsh-speaker, expressed that pride and identity in the local area could be seen in local place names. The nature of the Welsh language is that place names tend to be very descriptive of the place, referring to local landmarks, such as rivers, churches or valleys as a means of distinguishing themselves from neighbouring towns and villages, thus creating a stronger identity and sense of belonging to the place: 'Look at Pontypridd, 'the bridge by the earth'. The town is well-known for its iconic bridge, and even makes up part of the badge for the local rugby team' (Designer). This underlines the unique cultural characteristics and heritage of place associated with Relph's (1976) sense of place. Indeed, RCT's most recognisable product, Penderyn Whisky, is named after its place of origin, which is a significant aspect of its product characteristics, due to its natural water sources from the Brecon Beacons National Park. 
Participant H, a local food producer, commented that stereotypical images of 'The Valleys' were used in the branding of her company's logo, using images of rivers, tiled roofs, rugby posts and the wheels of coal mine shafts to create an identity for their product. This imagery was important for them in transmitting their depiction of the local area and their sense of belonging to consumers. Stereotypes are hard to avoid in place branding (Tellstrom et al., 2006), indeed, the use of origin labelling represents more than an expression of stereotypes, presenting an image of affection, pride and tradition (Fournier, 1998; Verlegh \& Steenkamp, 1999). The collection of images used in the branding of Participant H's company is a reflection of the multiple histories and identities upon which Massey's (1991) sense of place is based. Such images indicate the uniqueness of place that can be claimed in RCT. All participants agreed that a strong sense of belonging and pride was evident in the local community, particularly to the specific towns and villages where they lived.

\subsection{The Socio-economic Situation}

Despite the pride of place, it was widely recognized that many socio-economic problems exist in the area. Participants pointed to the de-industrialization of the area, using words such as 'deprived', 'downtrodden' and 'poor-looking', conveying a general feeling that the area is struggling economically with limited prospects for local residents. Built around the heavy industry boom of the late nineteenth century, the end of heavy industry has left a lasting mark as the area has struggled economically. This is particularly evident since the region qualified for EU Objective 1 funding, a programme aimed at promoting economic regeneration schemes in some of the EU's lagging areas (Welsh Government, 2015). As discussed by Ray (1998), cultural identity can help rural development, including using agri-food products as cultural markers in promoting the place. Indeed, local food products are a reflection of place, and economic and cultural benefits can be seen by fixing products to places (Everett and Aitchison 2008). This is recognised in RCT by the Rural Action Cwm Taf plan, which aims to support food action plans. In terms of food, participants A and D commented on the lack of local produce evident in the area, pointing towards the abundance of fast food outlets and the lack of local businesses or food producers. Participant I shared this view, referring to the types of businesses that can be seen in the area:

'A lot of businesses have gone. All there seems to be these days are charity shops and phone shops. You don't get to know so much about local food businesses, because you basically just go to a supermarket. You don't actually know what's local around here'.

This lack of outlets for local food and abundance of fast food outlets and chain stores is a sign of the placelessness and Disneyfication (Relph, 1976) of RCT, underlining the lack of authenticity for food (Tregear et al., 1998), and therefore questions the suitability of RCT for the development of a place brand. For Participant G, the lack of local shops and businesses acts as a barrier towards the community feeling. A lack of outlets where local people can meet means the community is less likely to thrive and the general sense of belonging has changed considerably during her lifetime. For Participant D, local businesses represent a possible solution in responding to the socio-economic problems within the community.

\subsection{Potential Benefits of a Rhondda Cynon Taf Logo}

As with the Kneafsey et al. (2001) study, focus group participants believed that creating a unique logo for RCT would have a positive impact upon the success of local food producers and the community, both regionally and nationally (see Figure 3). The role of the community in developing the logo was seen as a benefit as a way of building on the local identity, indeed, people make places (Cresswell, 2004), therefore the community-led approach to the logo is 
significant: 'It gives the community a sense of identity, because the logo is communitybased...I think it will make smaller businesses more accessible to the whole food industry' (Participant D).

Both food producers spoke positively of the potential logo benefits to their businesses. Participant $\mathrm{H}$ pointed to the recognition the logo could potentially bring to RCT and its food produce, making consumers aware of the local identity, as well as Welsh identity, which is important for the company. Crucially, Participant $\mathrm{H}$ sees the logo as an indicator of quality, an attribute with the potential to increase sales, both locally and internationally:

'I think this will enhance the branding and help recognize quality. The local community would also benefit from this because that product would become recognizable to the area...We want our customers to know that we are proud to be Welsh and that we actually produce in our valley'.

Another food producer, Participant F, echoes the effectiveness of the logo promoting local and Welsh food products, however emphasizes the need for the logo be part of a more extensive marketing campaign to provide consumers with information about the logo and enhance its meaning:

'Obviously the logo doesn't mean anything on its own. It has to be backed up by some kind of marketing campaign...that sells the spirit of the local community. People need to know about this logo, what it represents and somehow within their psyche, they need to get this idea that things with this logo are supporting their local community'.

\section{Discussion}

Undoubtedly, Rhondda Cynon Taf has a strong cultural heritage, as expressed by participants, however, this heritage is associated with the former heavy industry success of the region. Findings of the study point to a confused identity among respondents, with discussions of identity referring to the collective Valleys area, rather than to RCT specifically. This is in line with the Three Wales Model (Balsom, 1985) and the notion of a 'Welsh Wales' identity across the South Wales Valleys. Indeed, this was reflected in the final design of the logo (Figure 6), developed by the designer, based on the findings of the focus groups.

Figure 6: The final logo

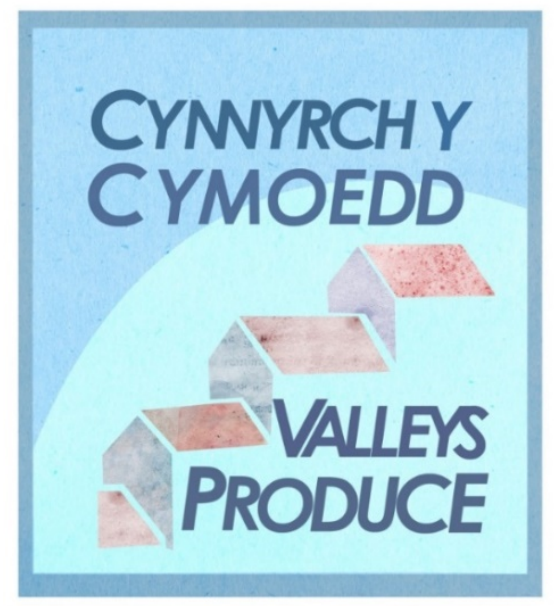

The logo projects an image of the cultural heritage of the former industrial areas of the South Wales Valleys, with blue and green colours representing the rivers and hills of the different 
valleys, and sloping roofs of terraced houses, a notorious feature of the area. Not specific to RCT, the effectiveness of the logo in promoting local RCT produce is therefore questionable. Papadopoulos (1993) warned of the dangers of blurred spatial distinctions in causing differing meanings of place, as is the case with RCT. The representation of place is important for the perception of product quality, especially for food products (Imene \& Georges, 2012). Given the limited food heritage in RCT, evident through a small number of producers and abundance of inauthentic food outlets, such as fast food or chain outlets (Tregear et al., 1998), it would be difficult to construct a reputation for quality food. Numerous examples exist of places that have successfully used regional branding to promote local food products, such as New Zealand, Cornwall or Brittany, however it could be argued that these places have built their brand around a pre-existing reputation for quality food products and a strong food heritage. Brittany is recognized as one of Europe's leading food-producing regions (Eurostat, 2018) and its products are closely associated with the cultural heritage of the region. Given the industrial heritage of RCT and lack of unique identity due to its creation as an administrative region, it is evident that regional branding for RCT would not add significant value to local food products. Indeed, the same is true for other similar regions.

Recognition of a region is essential for a brand of this kind to achieve any real value for the products it aims to promote, this stems from the region's identity (Roth \& Romeo, 1992). If consumers are not aware of a region, a brand of this kind would carry very little meaning. As Participant F stated, a broader marketing campaign is necessary to complement the logo. This is where value is created. Furthermore, the challenging socio-economic environment discussed in the focus groups underlines the limited food heritage of the region. The potential benefits of a logo like this are not disputed, with overall support for the logo being shown from participants in the focus groups. Indeed, the use of cultural branding through a logo could focus on the local heritage and evoke more positive images of the region (Fournier, 1998; Verlegh \& Steenkamp, 1999; Batra et al., 2000) as a means of overcoming the socio-economic problems of RCT discussed by participants. Economic benefits can be derived in places through the marketing of local foods (Ray, 1998; Everett \& Aitchison, 2008), but the limited food heritage of RCT means that this is more challenging. The final logo highlights the significance of the region's identity both in the eyes of its residents and consumers further afield. The choice of generic imagery to the South Wales Valleys and 'Valleys Produce' slogan, however, is a strong indicator that Rhondda Cynon Taf may not be a suitable region to have its own logo.

In view of this, the development of a logo representing food from Wales would be a more suitable solution, as this would represent a more meaningful depiction of place (Pike, 2009) for consumers. Support exists in Wales for a Welsh food logo (Kneafsey et al., 2001), indeed, participants pointed to benefits from the proposed regional logo to awareness for Welsh food (Figure 3). The identity of Wales and its reputation for food is such that consumers' awareness is relatively strong, as well as perceptions of quality. According to the Value of Welshness report (Food and Drink Wales, 2017), 85\% of consumers recognized Welsh produce as being of high quality, with consumers showing a desire for products made in Wales. A clear brand of origin could further enhance this. A 113\% increase in exports between 1999-2013 (Welsh Government, 2014) is a sign of increasing awareness and demand for Welsh foods in international markets. Quality in Welsh food is evident through the existence of 15 protected food names (UK Government, 2018). This is consistent with Resource-based View (RBV) theories (Barney, 1991) as a competitive advantage is achieved through exploiting unique and rare resources. Another unique resource is the Welsh language, seen as a distinctive attribute in marketing Welsh foods (Welsh Language Commissioner, 2014). If a sense of place is expressed through multiple histories and interactions (Massey, 1991) and constructed through economics, politics, gender, class, ethnicity and a variety of stories (Allen et al., 1998), the 
socio-economic and cultural identity of Wales therefore provides it with its unique sense of place.

\section{Conclusion}

The study presents evidence that place-based identities are naturally associated with food products, and companies who manage to manipulate their identity to create a positive consumer perception can add value to their products. Barriers to the implementation of this exist, however, in the negative perception of areas which are characterised by low economic activity, such as RCT. While local communities attempt to support local produce, in the case of RCT it is not always clear which produce is local to the area and producers face challenges in tempting local customers away from global supermarket chains who offer cheaper goods to a less prosperous society. Welsh regions do not derive the same economic value from regional produce compared to culturally similar regions such as Scotland or Brittany, because in the case of Brittany, it has developed its reputation for quality and authenticity over a long period of time, creating greater recognition as a leading food-producing region. Attempts to do this in RCT would be challenging and require time to build a reputation, especially since the region is more known for heavy industry than food. Wales, on the other hand, has seen increasing awareness and reputation for food in recent decades, most recognizably through Welsh Lamb (PGI) and the growing number of products with protected food names. In view of this, the creation of a logo representing Welsh produce would be more recognized for quality, thus adding value to Welsh produce, and could enhance the marketability of Welsh foods in a similar manner to origin brands in Brittany, Cornwall or New Zealand.

Both the literature and examples from Brittany, Cornwall and New Zealand imply that origin brands can provide value to places, however, this is less feasible for places which are, by nature, less distinctive. The study therefore makes recommendations for Welsh food producers to work together on a national level. The participatory community-led action-reflective approach adopted in this study underlines that people have a better understanding of the their community identity and are therefore integral in developing an origin brand that is representative of place, as was the case in Brittany. However, further research is necessary to investigate the effectiveness of the method, particularly to engage with a wide range of food producers, as well as local government and other stakeholders involved in regional development. The methodology used in this study could be replicated to understand the significance of a Welsh logo, however, this should include several focus groups held in different locations across Wales. Given the ambiguity of some place distinctions, greater research into the use of place branding in differing contexts is necessary to contribute to knowledge in this field, particularly research conducted from a consumer perspective.

\section{Acknowledgements}

This work was supported by the Creative Exchange Wales Network (CEWN) under a Creative Capacity grant.

\section{References}

Allen, J., Massey, D. B. and Cochrane, A. (1998) Rethinking the Region. Routledge, London. Anholt, S. (2016) Places: Identity, image and reputation. Springer, Basingstoke.

Baker, M. J. and Ballington, L. (2002) 'Country of origin as a source of competitive advantage’, Journal of Strategic Marketing, 10(2), pp. 157-168. 
Balsom, D. (1985) 'The Three-Wales Model', in Osmond, J. (ed.) The National Question Again. Gomer, Llandysul., pp. 1-17.

Barham, E. (2003) 'Translating terroir: the global challenge of French AOC labeling', Journal of Rural Studies, 19(1), pp. 127-138.

Barney, J. B. (1991) 'Firm Resources and Sustained Competitive Advantage', Journal of Management, 17(1), p. 99.

Batra, R. et al. (2000) 'Effects of Brand Local and Nonlocal Origin on Consumer Attitudes in Developing Countries’, Journal of Consumer Psychology, 9(2), pp. 83-95.

Bilkey, W. J. and Nes, E. (1982) 'Country-of-origin effects on product evaluations', Journal of international business studies, 13(1), pp. 89-100.

Braun, V. and Clarke, V. (2006) 'Using thematic analysis in psychology', Qualitative research in psychology. Taylor \& Francis, 3(2), pp. 77-101.

Buy NZ Made (2018) The Buy NZ Made Campaign. Available at: https://buynz.org.nz/ (Accessed: 15 October 2018).

Castree, N. (2001) 'Commodity fetishism, geographical imaginations and imaginative geographies’, Environment and Planning A, 33(9), pp.1519-1525.

Colomb, C. and Kalandides, A. (2010) 'The "Be Berlin” Campaign: Old Wine in New Bottles or Innovative Form of Participatory Place Branding?', in. Cheltenham, UK: 'Edward Elgar Publishing, Inc.'

Cornwall Council (2017) Made in Cornwall Scheme. Available at: https://www.cornwall.gov.uk/business/trading-standards/made-in-cornwall-scheme/ (Accessed: 8 July 2017).

Cresswell, T. (2004) Place: A Short Introduction. Wiley (Short Introductions to Geography). Chichester

Eurostat (2018) Eurostat Regional Yearbook.

Food and Drink Wales (2017) Value of Welshness: Shopper Desire for Welsh Produce.

Food and Drink Wales (2018) Food and drink exports briefing for 2017.

Fournier, S. (1998) 'Consumers and their brands: Developing relationship theory in consumer research’, Journal of consumer research, 24(4), pp. 343-353.

Harvey, D. (1996) Justice, Nature and the Geography of Difference. Oxford: Blackwell.

Imene, T. T. and Georges, G. (2012) 'Exploring Region of Origin Labeling Food Products as a New Experiential Brand Strategy’, Journal of Marketing Research \& Case Studies. IBIMA Publishing LLC, 2012, p. 1.

Kneafsey, M., Ilbery, B. and Jenkins, T. (2001) 'Exploring the Dimensions of Culture Economies in Rural West Wales’, Sociologia Ruralis. Blackwell Publishers Ltd, 41(3), pp. 296-310.

Kotler, P., Jatusripitak, S. and Maesincee, S. (1997) The marketing of nations: a strategic approach to building national wealth. Free Press.

Massey, D. B. (1991) ‘A global sense of place’, Marxism Today, pp. 24-29. 
McElwee, G., Smith, R. and Lever, J. (2017) 'Illegal activity in the "Horse Meat” Supply Chain: Understanding Food Fraud in the context of the 2013 Horsemeat Scandal', in Institute for Small Business and Entrepreneurship (ISBE) Annual conference. Belfast, pp. 1-33.

McNiff, J., Lomax, P. and Whitehead, J. (1996) You and your action research project. London: Routledge.

Miles, M. B., Huberman, A. M. and Saldana, J. (2014) Qualitative Data Analysis: A Methods Sourcebook. SAGE Publications, Thousand Oaks, California.

Morgan, N., Pritchard, A. and Pride, R. (2007) Destination Branding. Taylor \& Francis, Oxford.

ONS (2011) Census 2011. Available at: https://www.ons.gov.uk/census/2011census.

Papadopoulos, N. (1993) 'What Product-Country Images Are and Are Not', in N. Papadopoulos \& L. Heslop (ed.) Product-Country Images. Impact and Role in International Marketing. New York: International Business Press, pp. 3-35.

Pike, A. (2009) 'Brand and Branding Geographies’, Geography Compass. Blackwell Publishing Ltd, 3(1), pp. 190-213.

Produit en Bretagne (2018) Produit en Bretagne. Available at: http://www.produitenbretagne.bzh (Accessed: 14 February 2018).

Relph, E. C. (1976) Place and placelessness. Pion Limited (Research in Planning and Design Series).

Roth, M. S. and Romeo, J. B. (1992) 'Matching Product Catgeory and Country Image Perceptions: A Framework for Managing Country-Of-Origin Effects’, Journal of International Business Studies. Palgrave Macmillan Journals, 23(3), pp. 477-497.

Scotch Whisky Association (2018) Scotch Whisky 2017 Export Analysis.

Tellstrom, R., Gustafsson, I.-B. and Mossberg, L. (2006) 'Consuming heritage: The use of local food culture in branding’, Place Branding, 2(2), pp. 130-143.

Testa, S. (2011) 'Internationalization patterns among speciality food companies: some Italian case study evidence’, British Food Journal. Emerald Group Publishing Limited, 113(11), pp. 1406-1426.

Tregear, A. (2001) What is a 'typical Local Food'?: An Examination of Territorial Identity in Foods Based on Development Initiatives in the Agrifood and Rural Sectors. Centre for Rural Economy, University of Newcastle.

Tregear, A. and Gorton, M. (2005) 'Geographic origin as a branding tool for agri-food producers’, Society and Economy, 27(3), pp. 399-414.

Tregear, A., Kuznesof, S. and Moxey, A. (1998) 'Policy initiatives for regional foods: some insights from consumer research’, Food Policy, 23(5), pp. 383-394.

UK Government (2018) Protected food name scheme: UK registered products. Available at: https://www.gov.uk/government/collections/protected-food-name-scheme-uk-registeredproducts (Accessed: 14 February 2018).

Verlegh, P. W. J. and Steenkamp, J.-B. E. M. (1999) 'A review and meta-analysis of countryof-origin research’, Journal of economic psychology, 20(5), pp. 521-546. 
Warnaby, G. and Medway, D. (2013) 'What about the 'place'in place marketing?', Marketing Theory, 13(3), pp. 345-363.

Welsh Assembly Government (2014) Rural Action Cwm Taf Local Development Strategy. Available at: https://www.merthyr.gov.uk/media/1836/ract-leader-2014-2020-lds-final.pdf.

Welsh Government (2014) Towards Sustainable Growth: An Action Plan for the Food and Drink Industry 2014-2020.

Welsh Government (2015) A Summary of the ERDF and ESF Structural Fund Programmes in Wales.

Welsh Language Commissioner (2014) The value of the Welsh language to the food and drink sector in Wales Research report. Cardiff.

Zero2Five (2014) Welsh Food and Drink Directory 2014-15. 